\title{
Commentary: "Consistent superiority of selective serotonin reuptake inhibitors over placebo in reducing depressed mood in patients with major depression"
}

\begin{abstract}
Eiko I. Fried ${ }^{1 *}$, Lynn Boschloo ${ }^{2}$, Claudia D. van Borkulo ${ }^{2,3}$, Robert A. Schoevers ${ }^{2}$, Jan-Willem Romeijn ${ }^{4}$, Marieke Wichers ${ }^{2,5}$, Peter de Jonge ${ }^{2}$, Randolph M. Nesse ${ }^{6}$, Francis Tuerlinckx ${ }^{1}$ and Denny Borsboom ${ }^{3}$

${ }^{1}$ Faculty of Psychology, University of Leuven, Leuven, Belgium, ${ }^{2}$ Department of Psychiatry, Interdisciplinary Center Psychopathology and Emotion Regulation (ICPE), University Medical Center Groningen, University of Groningen, Groningen, Netherlands, ${ }^{3}$ Department of Psychology, University of Amsterdam, Amsterdam, Netherlands, ${ }^{4}$ Faculty of Philosophy, University of Groningen, Groningen, Netherlands, ${ }^{5}$ Department of Psychiatry and Psychology, School for Mental Health and Neuroscience, Maastricht University, Maastricht, Netherlands, ${ }^{6}$ School of Life Sciences, Arizona State University, Tempe, AZ, USA
\end{abstract}

Keywords: selective serotonin reuptake inhibitors, major depressive disorder, network analysis, antidepressants, symptomics

A commentary on

Michael Noll-Hussong,

University of Ulm, Germany

Reviewed by:

Albino J. Oliveira-Maia,

Champalimaud Foundation, Portugal

Tim Outhred,

University of Sydney, Australia

${ }^{*}$ Correspondence:

Eiko I. Fried

eiko.fried@gmail.com

Specialty section:

This article was submitted to Affective

Disorders and Psychosomatic

Research, a section of the journal

Frontiers in Psychiatry

Received: 25 June 2015 Accepted: 04 August 2015

Published: 21 August 2015

Citation:

Fried El, Boschloo L, van Borkulo CD, Schoevers RA, Romeijn J-W, Wichers $M$, de Jonge $P$, Nesse RM, Tuerlinckx $F$ and Borsboom D (2015) Commentary: "Consistent superiority of selective serotonin reuptake inhibitors over placebo in reducing depressed mood in patients with major depression".

Front. Psychiatry 6:117. doi: 10.3389/fpsyt.2015.00117
Consistent superiority of selective serotonin reuptake inhibitors over placebo in reducing depressed mood in patients with major depression

by Hieronymus F, Emilsson JF, Nilsson S, Eriksson E. Mol Psychiatry (2015). doi:10.1038/mp.2015.53

In the past decades, almost all research in psychiatry and clinical psychology has been directed at the level of disorders, such as major depressive disorder (MDD) or schizophrenia. As has been argued by many scholars in recent work, this organization of the psychiatric research program has yielded limited insights, which justifies the investigation of psychopathology at a more fine-grained level: the level of symptoms $(1,2)$. In the present letter, we indicate two primary directions for this research program, which we propose to call symptomics. We will focus our discussion on MDD specifically and discuss possibilities in relation to the recently published work by Hieronymus et al. (3).

Firstly, research has now shown that distinct depression symptoms, such as sad mood or insomnia differ in the risk factors that predispose them $(4,5)$, their underlying biology $(6,7)$, their response to specific life events $(8,9)$, and their impact on impairment of psychosocial functioning $(10,11)$ [for a review, see Ref. (1)]. This presents the first direction of the research agenda: to further investigate the properties in which individual symptoms differ from each other. The recently published work by Hieronymus et al. (3), "Consistent superiority of selective serotonin reuptake inhibitors over placebo in reducing depressed mood in patients with major depression", adds the differential reactivity of depression symptoms to antidepressant medication to the prior body of work. In their analysis of clinical trial data of 6,669 patients with MDD published in Molecular Psychiatry, the authors document that depressive symptoms responded differentially to treatment with selective serotonin reuptake inhibitor (SSRI) antidepressants. Pooled effect sizes ranged from 0 (for symptoms, such as gastrointestinal and genital symptoms) to 0.44 (for depressed mood, a core symptom of depression). Hieronymus et al. (3) argue that these findings are consistent with prior antidepressant research that found differential treatment effects on symptoms and stress the importance of analyzing individual depression symptoms in future studies. We would like to extend their claim: these results, along with previous symptom-based findings, mandate the examination of symptom-specific effects throughout the realm of psychopathology. 


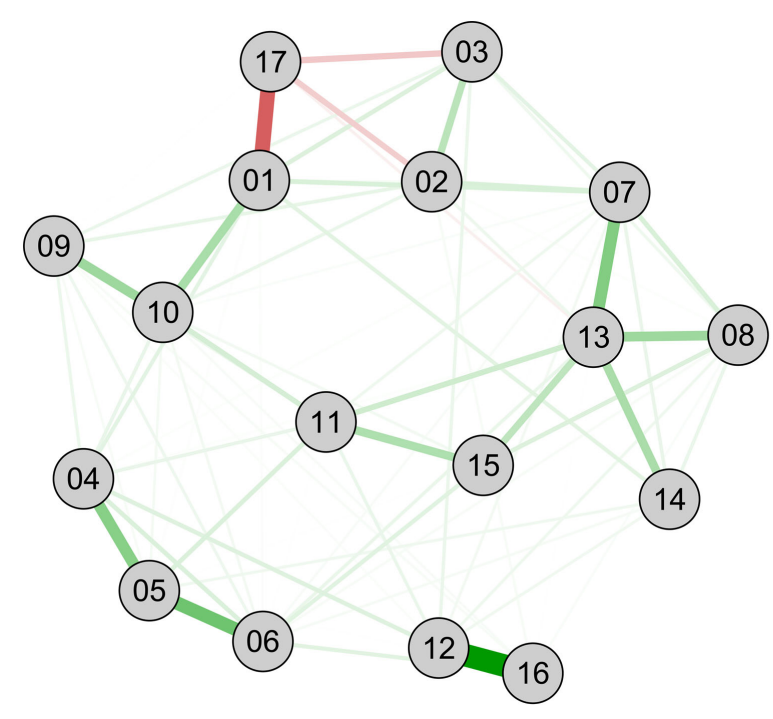

01 - Depressed mood
02 - Feelings of guilt
03 - Suicide
04 - Insomnia, early
05 - Insomnia, middle
06 - Insomnia, late
07 - Work and activities
08 - Retardation
09 - Agitation
10 - Anxiety, psychic
11 - Anxiety, somatic
12 - Gastrointestinal problems
13 - Somatic symptoms, general
14 - Genital symptoms
15 - Hypochondriasis
16 - Loss of weight
17 - Insight

FIGURE 1 | Network of 17 HRSD depression symptoms. Green lines represent positive associations, red lines negative associations, and thickness and brightness of an edge indicate the strength of the association.

The second research direction is the investigation of distinct patterns of causes and effects in which symptoms operate. Network analysis provides a tool to investigate these specific associations between symptoms that can sustain mental disorders (2). Contrasting the traditional explanation that the co-occurrence of symptoms (such as the depressive syndrome) is due to one underlying shared origin (MDD causes depression symptoms), networks conceptualize depression as a complex dynamic system of mutually reinforcing associations $(12,13)$. Figure 1 presents an example of such a psychopathological network - in the form of a Markov random field (MRF) - for the Hamilton Depression Rating Scale (HRSD), the same instrument analyzed by Hieronymus et al. (3). We computed the network from the enrollment symptom data of 3,467 patients from the antidepressant trial "sequenced treatment alternatives to relieve depression” (STAR $\left.{ }^{\star} \mathrm{D}\right)(14)$, a dataset that can be requested at the NIMH. The network can be viewed as a tentative estimate of the causal skeleton of a disorder and may be used to gauge which symptoms are most central in receiving input, and/or sending out influences into the system (15). Applying a network perspective to the paper by Hieronymus et al. (3) gains considerable analytic power. For example, the centrality of the STAR ${ }^{\star}$ D HRSD symptoms, as measured by their closeness to other symptoms in the network (2), correlates $r=0.53$ $(p<0.05)$ with the symptom effect sizes reported by the authors. This means that more central symptoms exhibit greater reactivity to the intervention. In addition, symptoms with a higher closeness have a higher reported baseline severity $(r=0.60, p<0.05)$ and symptoms with a higher baseline severity exhibit a (much) larger effect size $(r=0.77, p<0.001)$. Thus, an interesting three-way pattern arises with more central HRSD items exhibiting higher reported means and higher reported reactivity to interventions.

While we can only speculate as to what produces this intriguing pattern of effects, the most important message is that focusing on the level of symptoms and analyzing the causal relations among them is likely to extend our understanding of psychopathology directly and significantly. The widespread reliance on disorders and the associated focus on symptom sum-scores in investigations of the biology and treatment of psychopathology may have concealed crucial insights $(1,16)$. A number of multivariate approaches have been developed for, and used with, depression symptoms previously, including structural equation models and network analyses $(4,9)$; in addition, time-series analysis studying network dynamics has become available as a tool to zoom in on the micro-level interactions among symptoms (17). Paying close attention to symptoms and their dynamics may have important clinical implications. Due to the highly heterogeneous nature of MDD (18, 19), individuals may differ substantially from each other not only in the symptoms they exhibit, but also in the way their symptoms are related to contextual influences, and in the way symptoms shape each other across time. A treatment focus on especially prevalent and central symptoms, instead of the categorically defined and heterogeneous disorders itself, may help increase the currently disappointing levels of treatment response (20). A broader investigation of symptom-specific treatment effects similar to the study performed by Hieronymus et al. (3) would enable clinical trials to match participants to specific treatments, based on their symptom profiles and dynamics.

In summary, symptomics invites the application of new modeling efforts to the level of individual symptoms as fundamental building blocks of mental disorders. As such, it may herald a time of renewed research energy that could, finally, provide an inroad to achieve real understanding of the mechanisms underlying psychopathology.

\section{Acknowledgments}

The $\operatorname{STAR}^{\star} \mathrm{D}$ study was supported by NIMH Contract \#N01MH90003 to the University of Texas Southwestern Medical Center (http://www.nimh.nih.gov). The ClinicalTrials.gov identifier is NCT00021528. This manuscript reflects the views of the authors and may not reflect the opinions or views of the $\mathrm{STAR}^{\star} \mathrm{D}$ study investigators or the NIMH. 


\section{References}

1. Fried EI, Nesse RM. Depression sum-scores don't add up: why analyzing specific depression symptoms is essential. BMC Med (2015) 13:72. doi:10.1186/s12916015-0325-4

2. Borsboom D, Cramer AOJ. Network analysis: an integrative approach to the structure of psychopathology. Annu Rev Clin Psychol (2013) 9:91-121. doi:10. 1146/annurev-clinpsy-050212-185608

3. Hieronymus F, Emilsson JF, Nilsson S, Eriksson E. Consistent superiority of selective serotonin reuptake inhibitors over placebo in reducing depressed mood in patients with major depression. Mol Psychiatry (2015). doi: $10.1038 / \mathrm{mp} .2015 .53$

4. Fried EI, Nesse RM, Zivin K, Guille C, Sen S. Depression is more than the sum score of its parts: individual DSM symptoms have different risk factors. Psychol Med (2014) 44:2067-76. doi:10.1017/S0033291713002900

5. Lux V, Kendler KS. Deconstructing major depression: a validation study of the DSM-IV symptomatic criteria. Psychol Med (2010) 40(10):1679-90. doi:10. 1017/S0033291709992157

6. Lamers F, Vogelzangs N, Merikangas KR, de Jonge P, Beekman ATF, Penninx BWJH. Evidence for a differential role of HPA-axis function, inflammation and metabolic syndrome in melancholic versus atypical depression. Mol Psychiatry (2013) 18(6):692-9. doi:10.1038/mp.2012.144

7. Myung W, Song J, Lim S-W, Won H-H, Kim S, Lee Y, et al. Genetic association study of individual symptoms in depression. Psychiatry Res (2012) 198(3):400-6. doi:10.1016/j.psychres.2011.12.037

8. Keller MC, Neale MC, Kendler KS. Association of different adverse life events with distinct patterns of depressive symptoms. Am J Psychiatry (2007) 164(10):1521-9. doi:10.1176/appi.ajp.2007.06091564

9. Fried EI, Bockting C, Arjadi R, Borsboom D, Amshoff M, Cramer OJ, et al. From loss to loneliness: the relationship between bereavement and depressive symptoms. J Abnorm Psychol (2015) 124:265-65. doi:10.1037/abn0000028

10. Fried EI, Nesse RM. The impact of individual depressive symptoms on impairment of psychosocial functioning. PLoS One (2014) 9(2):e90311. doi:10.1371/ journal.pone.0090311

11. Tweed DL. Depression-related impairment: estimating concurrent and lingering effects. Psychol Med (1993) 23(02):373-86. doi:10.1017/ S0033291700028476

12. Van de Leemput IA, Wichers MC, Cramer AOJ, Borsboom D, Tuerlinckx F, Kuppens P, et al. Critical slowing down as early warning for the onset and termination of depression. Proc Natl Acad Sci U S A (2014) 111(1):87-92. doi:10.1073/pnas.1312114110

13. Bringmann LF, Lemmens LHJM, Huibers MJH, Borsboom D, Tuerlinckx F. Revealing the dynamic network structure of the beck depression inventory-II. Psychol Med (2015) 45:747-57. doi:10.1017/S0033291714001809

14. Rush AJ, Fava M, Wisniewski SR, Lavori PW, Trivedi MH, Sackeim HA, et al. Sequenced treatment alternatives to relieve depression $\left(\operatorname{STAR}^{\star} \mathrm{D}\right)$ : rationale and design. Control Clin Trials (2004) 25(1):119-42. doi:10.1016/S0197-2456(03) 00112-0

15. Costantini G, Epskamp S, Borsboom D, Perugini M, Mõttus R, Waldorp LJ, et al. State of the aRt personality research: a tutorial on network analysis of personality data in R. J Res Pers (2015) 54(R Special Issue):13-29. doi:10.1016/ j.jrp.2014.07.003

16. Fried EI. Problematic assumptions have slowed down depression research: why symptoms, not syndromes are the way forward. Front Psychol (2015) 6:309. doi:10.3389/fpsyg.2015.00309

17. Wichers MC. The dynamic nature of depression: a new micro-level perspective of mental disorder that meets current challenges. Psychol Med (2013) 616:1-12. doi:10.1017/S0033291713001979

18. Fried EI, Nesse RM. Depression is not a consistent syndrome: an investigation of unique symptom patterns in the $\mathrm{STAR}^{\star} \mathrm{D}$ study. J Affect Disord (2015) 172:96-102. doi:10.1016/j.jad.2014.10.010

19. Olbert CM, Gala GJ, Tupler LA. Quantifying heterogeneity attributable to polythetic diagnostic criteria: theoretical framework and empirical application. J Abnorm Psychol (2014) 123(2):452-62. doi:10.1037/a0036068

20. Pigott HE, Leventhal AM, Alter GS, Boren JJ. Efficacy and effectiveness of antidepressants: current status of research. Psychother Psychosom (2010) 79(5):267-79. doi:10.1159/000318293

Conflict of Interest Statement: The authors declare that the research was conducted in the absence of any commercial or financial relationships that could be construed as a potential conflict of interest.

Copyright (c) 2015 Fried, Boschloo, van Borkulo, Schoevers, Romeijn, Wichers, de Jonge, Nesse, Tuerlinckx and Borsboom. This is an open-access article distributed under the terms of the Creative Commons Attribution License (CC BY). The use, distribution or reproduction in other forums is permitted, provided the original author(s) or licensor are credited and that the original publication in this journal is cited, in accordance with accepted academic practice. No use, distribution or reproduction is permitted which does not comply with these terms. 